\title{
Prognostic factors in glioblastoma multiforme
}

\author{
Leonardo Welling ${ }^{1}$, José Carlos Lynch², Celestino Pereira ${ }^{3}$, Ricardo Andrade4, \\ Fabiana Polycarpo Hidalgo ${ }^{1}$, Alessandra G. L. Pereira ${ }^{5}$, Claúdia Escoteguy ${ }^{6}$
}

Serviço de Neurocirurgia do Hospital dos Servidores do Estado do Rio de Janeiro, RJ, Brasil.

\begin{abstract}
Objective: To study if the prognosis variables such as age, the Karnofsky Performance Status (KPS), extension of tumor removal by surgery, radiotherapy and tumor volume influenced the survival of patients with glioblastoma multiforme (GBM). Method: Retrospective analysis of GBM patients operated at Hospital dos Servidores do Estado between 1998 and 2008. Results: We could observe that age, the KPS and radiotherapy influenced the survival. The other variables did not have any prognosis implications. Conclusions: Despite many researches and many improvements regarding the diagnosis and the surgical techniques, the survival of patients with GBM has not changed in the last 30 years and is a therapeutic challenge. The surgical resection followed by radiotherapy is the standard treatment for patients with GBM. The importance of each variable in the patient's prognosis is still to be established in the multivariate analyzes.
\end{abstract}

\section{KEYWORDS}

Glioblastoma multiforme. Prognosis. Survival.

\section{RESUMO}

Fatores prognósticos no glioblastoma multiforme

Objetivo: Observar se os fatores prognósticos dos pacientes com glioblastoma multiforme (GBM), como a idade, o Karnofsky Performance Status (KPS), a extensão da remoção tumoral, a realização de radioterapia e o volume tumoral, influenciam a sobrevida dos pacientes. Método: Realizamos uma revisão retrospectiva dos prontuários dos pacientes operados no Hospital dos Servidores do Estado do Rio de Janeiro no período de 1998 a 2008. Resultados: Observamos que a idade, a realização da radioterapia e o KPS influenciaram a sobrevida dos pacientes. As demais variáveis não tiveram implicações prognósticas. Conclusões: Apesar de inúmeras pesquisas, a sobrevida dos pacientes com GBM praticamente não se alterou nos últimos 30 anos, permanecendo como um desafio terapêutico. A ressecção cirúrgica complementada com radioterapia ainda é o tratamento de escolha. O papel de cada variável no prognóstico dos pacientes ainda está por ser definida nas análises multivariadas.

\section{PALAVRAS-CHAVE}

Glioblastoma multiforme. Prognóstico. Sobrevida.

\section{Introduction}

The cerebral tumor incidence corresponds to 16:100,000 hab/year. The gliomas are $60 \%$ of the primary cerebral tumors and the glioblastoma multiforme (GBM) represents 50\% among all the gliomas. According to the WHO (World Health Organization) classification, the GBM has the highest malignancy grade (grade IV) besides affecting all ages, especially between 45 and 70 years. ${ }^{4,17}$

The GBM can result from a transformation of a low-grade astrocytoma. The primary GBM is the one, when detected, that shows its classical shape without previous malignant transformation. ${ }^{3,5}$

Despite progress in neurosurgery, radiotherapy and the clinical oncology the GBM survival has not

Médico-residente do Serviço de Neurocirurgia do Hospital dos Servidores do Estado do Rio de Janeiro (HSE-RJ).

Chefe do Serviço de Neurocirurgia do HSE-RJ.

Preceptor dos residentes do Serviço de Neurocirurgia do HSE-RJ.

Chefe de clínica do Serviço de Neurocirurgia do HSE-RJ.

5 Médica-residente do Serviço de Epidemiologia do HSE-RJ.

6 Chefe do Serviço de Epidemiologia do HSE-RJ. 
changed in the last 30 years. Surgery and radiotherapy (RT) have kept themselves as the basic treatment being complemented with chemotherapy. ${ }^{12}$

According to several authors, age, the Karnofsky Performance Status (KPS), tumor removal and radiotherapy influence the patients' survival. ${ }^{9,10,11,13,19}$

This study aims to observe if the GBM prognostic factors previously mentioned may have influenced our patients' survival.

\section{Material and methods}

We have performed a retrospective analysis. The surgery descriptions, tomographic and magnetic resonance images of 58 patients with confirmed histological diagnosis of GBM were included. All these cases involved 18 year-old or older patients with supratentorial GBM. All of them were operated at the Hospital dos Servidores do Estado (HSE) from 1998 to 2008.

We have excluded 13 cases whose archives were incomplete. We evaluated 45 patients at this current study. The mean follow-up was 7.7 months varying from 1 to 50 months. We checked if age, the KPS, the surgical removal (total versus partial), radiotherapy, tumor volume and the symptoms duration influenced the patients' survival. Univariate analyses (Kaplan-Meier Curve) were performed.

\section{Results}

We identified $40(89 \%)$ primary GBM cases and 5 (11\%) secondary. There were 23 female patients $(51 \%)$ and $22(49 \%)$ were male. The operative mortality occurred in $3(6.7 \%)$ patients in the series. The average survival was 7.7 months (Figure 1). The demographic data, signs and symptoms can be observed in tables 1 and 2 .

We have analyzed the following risk factors:

1) Age - The average age was 56 years, varying from 27 to 80 year; $31(68.9 \%)$ cases were 50 year-old or older. Regarding the age, we observed that patients younger than 50 yearold had survived longer, which is statistically significant $(\mathrm{p}=0.01)$ (Figure 1$)$.

2) Karnofsky Performance Status - The KPS was the same or over 70 in $24(53.3 \%)$ patients. The average was 70 . The mean follow-up in patients with KPS lower than 70 was 4.3 months, with the KPS higher or the same as 70 was

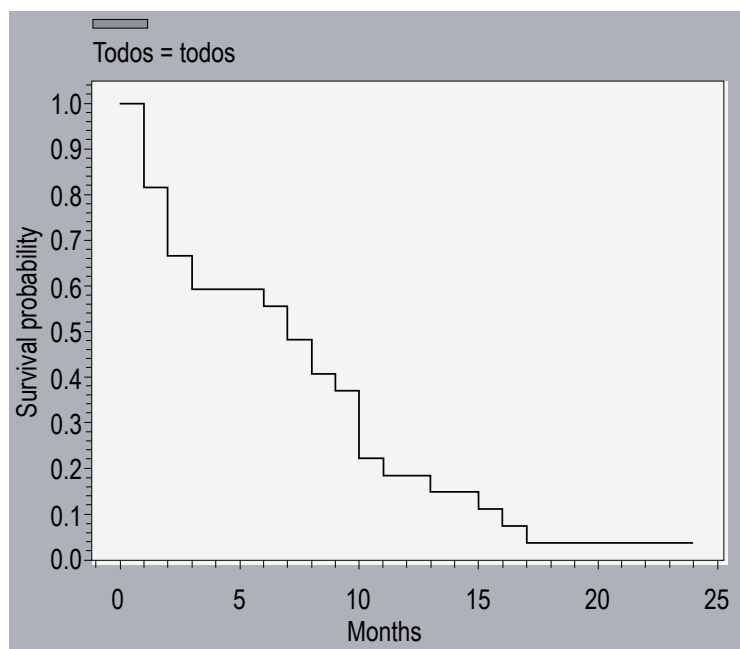

Figure 1 - Survival probability of 45 GBM patients, HSE 19862008 (Kaplan-Meier Method).

Table 1

Demographic and clinical data of 45 GBM patients operated at HSE

\begin{tabular}{ll}
\hline Male & $(22) 49 \%$ \\
Female & $(23) 51 \%$ \\
Average age & 56 years old $(27-80)$ \\
Symptoms duration & 3 months $(01-08)$ \\
KPS & $70(40-100)$ \\
Tumor volume & $71 \mathrm{~cm}^{3}$ \\
Intracranial hypertension & $25(55 \%)$ \\
Focal signs & $22(49 \%)$ \\
Seizures & $13(29 \%)$ \\
\hline
\end{tabular}

\begin{tabular}{|c|c|c|c|}
\hline \multicolumn{4}{|c|}{$\begin{array}{c}\text { Table } 2 \\
\text { Distribution of some characteristics stratified by surgical } \\
\text { resection in } 45 \text { GBM patients, HSE 1986-2008 }\end{array}$} \\
\hline & Subtotal resection & Total resection & $\mathrm{P}$ \\
\hline Male & $12(52.2 \%)$ & $10(45.5 \%)$ & 0.652 \\
\hline Female & $11(47.8 \%)$ & $12(54.5 \%)$ & \\
\hline Age & & & 0.457 \\
\hline$\geq 50$ years old & $17(73.9 \%)$ & $14(63.6 \%)$ & \\
\hline$<50$ years old & $6(26.1 \%)$ & $8(36.4 \%)$ & \\
\hline KPS & & & 0.024 \\
\hline$\geq 70$ & $8(34.8 \%)$ & $16(72.7 \%)$ & \\
\hline$<70$ & $15(65.2 \%)$ & $6(27.3 \%)$ & \\
\hline Radiotherapy & & & 0.855 \\
\hline Yes & $14(60.9 \%)$ & $13(59.1 \%)$ & \\
\hline No & $9(39.1 \%)$ & $9(40.9 \%)$ & \\
\hline Operative mortality & $2(8.7 \%)$ & $1(4.5 \%)$ & 0.968 \\
\hline Tumor volume & & & 0.867 \\
\hline$\geq 40 \mathrm{~cm}$ & $12(5.2 \%)$ & $13(59.1 \%)$ & \\
\hline$<40 \mathrm{~cm}$ & $11(47.8 \%)$ & $9(40.9 \%)$ & \\
\hline
\end{tabular}


10.5 months. This comparison was statistically significant (Mann-Whitney Test $p=0.01$ ) and we could also observe that patients with the KPS higher than 70 showed a longer survival, which is statistically significant, as observed in figure 2 $(\mathrm{p}=0.004)$.

3) Radiotherapy - The RT was daily applied, five times a week for six weeks in 27 patients $(60 \%)$. The survival curve showed that patients submitted to RT had a longer survival, which is statistically significant, as observed in figure 3 $(\mathrm{p}=0.01)$.

4) Tumor resection - We performed total resection in $22(48.9 \%)$ patients and subtotal removal in $23(51.1 \%)$. We established that the resection extension did not allow a reliable impression of surgical extension since we had such a

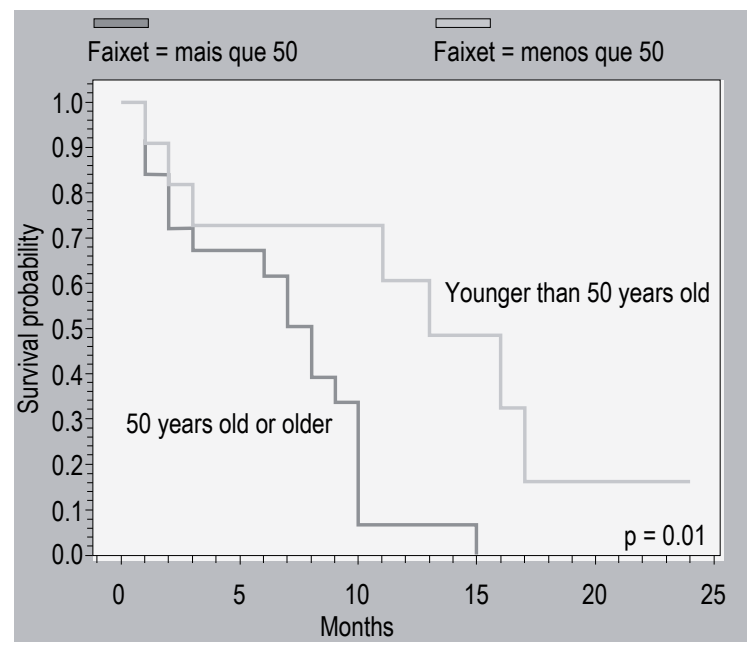

Figure 2 - Survival probability stratified by age in 45 GBM patients, HSE 1986-2008 (Kaplan-Meier Method).

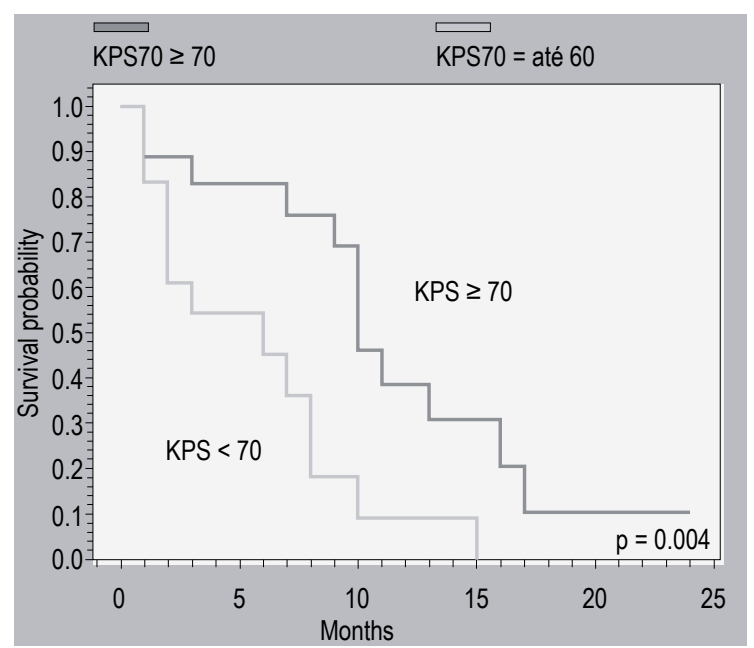

Figure 3 - Survival probability stratified by KPS in 45 GBM patients, HSE 1986-2008 (Kaplan-Meier Method). progress regarding the imagenology during this study. The evaluation was performed through tomography in the first patients in the series. We believe such exam cannot allow appropriate residual tumor measures, which may have caused an undetermined evaluation regarding the first cases of this current series. The group distribution according to the resection extension can be evaluated in table 2 . The difference observed in the survival curve (Figure 4) concerning the resection extension was not statistically significant $(\mathrm{p}=0.3)$.

5) Tumor volume - We found the average tumor volume (estimated by Cavalieri's Method) of $71 \mathrm{~cm}^{3}$. There was no influence on the survival $(p=0.5)$ when we compared bigger tumors or smaller than $40 \mathrm{~cm}^{3}$.

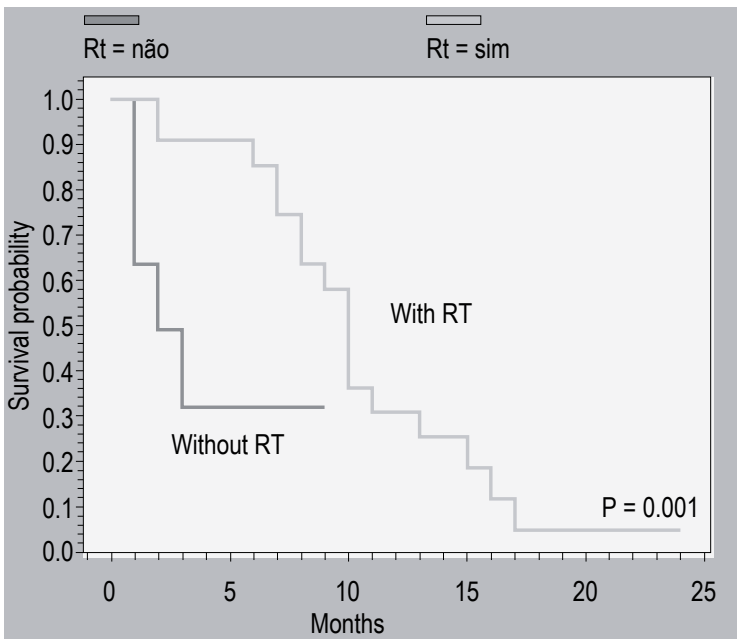

Figure 4-Survival probability stratified by adjuvant radiotherapy (RT) in 45 GBM patients, HSE 1986-2008 (Kaplan-Meier Method).

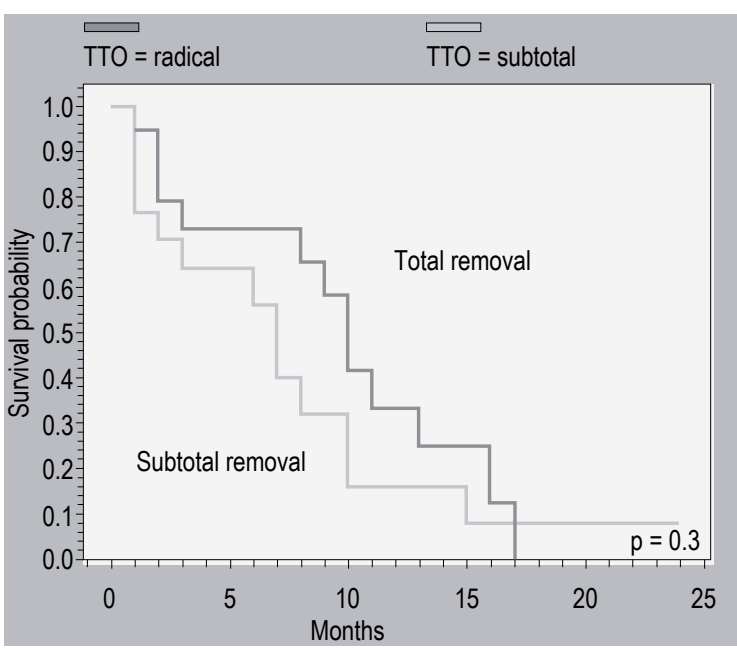

Figure 5 - Survival probability stratified by tumor resection in 45 GBM patients, HSE 1986-2008 (Kaplan-Meier Method). 


\section{Discussion}

Unfortunately, the GBM survival has not changed in the last 30 years. The average survival has kept less than a year and most of patients' death occurred up to two years. ${ }^{1-3,5,10,18}$

\section{Non-modifiable prognostic factors}

1) Age - The GBM patients survival is directly related to age. ${ }^{1,2,6,10,13,15}$ According to Curran et al. ${ }^{2}$ the age over 50 years is the prognostic factor which negatively impacts on the survival. Barker et al. ${ }^{1}$ mention age as an independent variable to obtain good results in radiotherapy. Some studies ${ }^{6}$ inform that age influences the tumor removal extension, which may partly explain more survivals in younger patients in our series. There was no difference in the tumor removal extension related to age (Table 2). We observed the survival in patients (with statistic significance) younger than 50 year-old, i.e., the younger patients showed a better prognosis independently of the resection extension ( $\mathrm{p}=$ 0.01) (Figure 1).

2) Karnofsky Performance Status - Some studies used limit values of 70 while others chose 80 . Several authors declare that patients with higher KPS showed longer survival rather those with lower KPS. ${ }^{2,6,8,10,14}$ According to Kreth et al. ${ }^{9}$ the youngest individuals tend to show higher KPS, which may be considered a confusing variable in the multivariate statistical analysis models. In Lacroix et al. series ${ }^{10} 75 \%$ of patients showed KPS higher than 80 . The patients with KPS higher than 70 had a mean follow-up of 10.5 months in our study. We observed that $72 \%$ of patients with KPS $>70$ were submitted to the total resection while only $27 \%$ in patients with KPS $<70$. This data can have influenced the survival. The patients with KPS higher than 70 showed longer survival than those ones with lower KPS in our series. We can observe as statistically significant data in figure $2(p=0.004)$.

3) Tumor volume - Several papers identify the tumor volume as a non- prognostic factor. ${ }^{8,9,14,21}$ On the other hand, Jeremic et al. ${ }^{6}$ mention that tumors smaller than $40 \mathrm{~cm}^{3}$ show better prognosis. The average tumor volume in Lacroix et al. ${ }^{10}$ series was $34 \mathrm{~cm}^{3}$. The average tumor value was $71 \mathrm{~cm}^{3}$ in our set of cases. We did not observe any influence in the survival $(\mathrm{p}=$ 0.5 ) when comparing the tumor groups bigger or smaller than $40 \mathrm{~cm}^{3}$.

\section{Modifiable prognostic factors}

1) Surgical treatment - The surgical treatment is the initial approach to glioblastoma. Besides providing the histology, the surgery may be an important prognostic factor. Lacroix et al. ${ }^{10}$ show the resection over $98 \%$ of the lesion modifies the patient's survival. Laws et al. ${ }^{11}$ mention that the tumor resection is better than biopsy. Many other authors also believe that the total removal of GBM may influence the survival. ${ }^{6,12,13,15,19}$ McGirt et al. ${ }^{13}$ analyzed 451 GBM patients and had 13 months of average survival of those submitted to the total resection. However, other authors did not find any relation between total removal and survival. ${ }^{8,9,16,18}$ When comparing the patients submitted to total resection vers $u$ s biopsy, Kreth et al. ${ }^{9}$ got average survival of 37 and 33 weeks respectively but without any statistic significance. Kowalczuck et al. ${ }^{8}$ described the resection extension as less important than other factors previously analyzed such as age, the KPS and RT in a retrospective study. The patients submitted to a total resection had a longer survival without getting any statistic significance in our series $(p=0.3)$.

2) Radiotherapy - The role of RT in treating glioblastoma has already been established. ${ }^{1,2,6,8,12,22}$ Mineo et al. ${ }^{15}$ mention radiotherapy as the factor with most influence on the prognosis independently of age, the KPS and the surgical extension. According to Barker et al. ${ }^{1}$ the radiotherapy has more influence in younger patients. The biopsy followed by a complementary radiotherapy is applied to patients in poor functional status. ${ }^{9}$ According to several publications, ${ }^{2,6,8,12}$ we also demonstrate the importance of RT in the patients with increased survival as shown in figure $3(\mathrm{p}=0.001)$.

\section{Conclusion}

The GBM has the highest maligancy grade in the astrocitic tumor group. It is the most common primary central nervous system tumor in adults besides being a therapeutic challenge. The maximum surgical resection followed by RT is still the standard treatment for the GBM patients. The importance of each variable in the patient's prognosis is still to be established in the multivariate analyzes. We have found out that younger patients with better KPS and treated with RT show a better prognosis. 


\section{References}

1. Barker FG, Prados MD, Chang SM, Gutin PH, Lamborn $\mathrm{KR}$, Larson DA, et al. Radiation response and survival time in patients with glioblastoma multiforme. J Neurosurg. 1996;84:442-8.

2. Curran WJ Jr, Scott CB, Horton J, Nelson JS, Weinstein AS, Fischbach AJ, et al. Recursive partitioning analysis of prognostic factors in three Radiation Therapy Oncology Group malignant glioma trials. J Natl Cancer Inst. 1993;85:704-10.

3. De angelis LM. Brain tumors. N Engl J Med. 2001;344: 114-23.

4. Deorah S, Lynch CF, Sibenaller ZA, Ryken TCR. Trends in brain cancer incidence and survival in the United States: surveillance, epidemiology, and end results program, 1973 to 2001. Neurosurg Focus. 2006;20:1-7.

5. Henson JW. Treatment of glioblastoma multiforme. Arch Neurol. 2006;63:337-41.

6. Jeremic B, Milicic B, Grujicic D, Dagovic A, Aleksandrovic $\mathrm{J}$, Nikolic N. Clinical prognostic factors in patients with malignant glioma treated with combined modality approach. Am J Clin Oncol. 2004;27:195-204.

7. Kleihues P, Ohgaki H. Genetic Pathways to Primary and Secondary glioblastomas Am J Pathol. 2007;170:1445-53.

8. Kowalczuk A, Macdonald RL, Amidei C, Dorhmann G, Erickson RK, Hekmatpanah J, et al. Quantitative imaging study of extent of surgical resection and prognosis of malignant astrocytomas. Neurosurgery. 1997;41:1028-38.

9. Kreth FW, Berlis A, Spiropoulou V, Faist M, Scheremet $R$, Rossner $R$, et al. The role of tumor resection in the treatment of glioblastoma multiforme in adults. Cancer. 1999;86:2117-23.

10. Lacroix M, Abi-Said D, Fourney DR, Gokaslan ZL, Shi W, DeMonte $F$, et al. A multivariate analysis of 416 patients with glioblastoma multiforme: Prognosis, extent of resection, and survival. J Neurosurg. 2001;95:190-8.

11. Laws ER, Parney IF, Huang W, Anderson F, Morris AM, Asher A, et al. Glioma Outcomes Investigators Survival following surgery and prognostic factors for recently diagnosed malignant glioma: data from the Glioma Outcomes Project. J Neurosurg. 2003;99:467-73.

12. Mason WP, Maestro RD, EisenstaT D, Forsyth P, Fulton $\mathrm{D}$, Laperrière $\mathrm{N}$, et al. Canadian recommendations for the treatment of glioblastoma multiforme. Curr Oncol. 2007;14:110-7.
13. McGirt MJ, Chaichana KL, Ghatinji M Attenello FJ, Than K, Olivi A, et al. Independent association of extent of resection with survival in patients with malignant brain astrocytomas. J Neurosurg. 2009;110:156-62.

14. Miller PJ, Hassanein RS, Giri S, Kimler GF, O'Boynick P, Evans RG. Univariate and multivariate statistical analysis of high-grade gliomas: the relationship of radiation dose and other prognostic factors. Int J Radiat Oncol Biol Phys. 1990;19:275-80.

15. Mineo JF, Bordron A, Baroncini M, Ramirez C, Maurage A, Blond $\mathrm{S}$, et al. Prognosis factors of survival time in patients with glioblastoma multiforme: a multivariate analysis of 340 patients. Acta Neurochir (Wien). 2007;149:245-53.

16. Nazzaro JM, Neuwelt EA. The role of surgery in the management of supratentorial intermediate and high-grade astrocytomas in adults. J Neurosurg. 1990;73:331-4.

17. Pinto LW, Chimelli L. Componente oligodendroglial e neuronal em glioblastomas. Arq Neuropsiquiatr. 2004;62:1074-8.

18. Quigley MR, Maroon JC. The relationship between survival and the extent of resection in patients with supratentorial malignant gliomas. Neurosurgery. 1991;29:385-9.

19. Stummer W, Reulen HJ, Meinel T, Pichmeiler U, Schumacher $\mathrm{W}$, Ton JC, et al. Extent of resection and survival in glioblastoma multiforme: identification and adjustment for bias. Neurosurgery. 2008;62:564-76.

20. Stupp R, Mason WP, Van den Bent M, Weller M, Fisher B, Taphoorn MJ, et al. Radiotherapy plus concomitant and adjuvant temozolomide for glioblastoma. N Engl J Med. 2005;352:987-96

21. Wood JR, Green SB, Shapiro WR. The prognostic importance of tumor size in malignant gliomas: a computed tomography scan study by the Brain Tumor Cooperative Group. J Clin Oncol. 1988;6:338-43.

22. Yuile P, Dent O, Cook R, Biggs M, Little N. Survival of glioblastoma patients related to presenting symptoms, brain site and treatment variables. J Clin Neurosci. 2006;13: 747-51.

\section{Endereço para correspondência}

Leonardo Welling

Rua Antonio Moro, 45

84050-440 - Ponta Grossa, PR, Brasil 